\title{
Exhaled and nasal nitric oxide measurements: recommendations
}

\author{
S. Kharitonov*, K. Alving**, P.J. Barnes*
}

Proposed by the European Respiratory Society Task Force "Measurement of Nitric Oxide in Exhaled Air"

\section{Contents}

1. Background

2. Chemiluminescence analysers and general equipment
2.1 System design
2.2 Equipment requirements
2.3 Quality control
2.4 Infection control

3. Exhaled NO: standardization issues

3.1 Inspiratory and ambient NO

3.2 Procedural sources of variation in NO measurements

3.2.1 Patient-related factors

3.2.2 Inspiratory manoeuvre

3.2.3 Exhalation parameters: pressure, flow and volume

3.2.4 Expiratory manoeuvre

3.3 Interval between measurements

4. Nasal NO measurements

5. Factors influencing NO measurements

5.1 Height, weight, age and sex

5.2 Water vapour

5.3 Physical exercise

5.4 Respiratory pattern

5.5 Breathholding

5.6 Cigarette smoking

5.7 Alcohol

5.8 Menstrual cycle and pregnancy

5.9 Upper respiratory tract infection

5.10 Diet and expelled air

6. Normal NO release in airways

6.1 Normal exhaled and nasal NO

6.2 Expression of $\mathrm{NO}$ values

7. Other inflammatory markers in exhaled air

8. Future directions

\section{Background}

Nitric oxide (NO) gas, which is produced by various cells within the respiratory tract, is detectable in the exhaled air [1, 2], and plays an important role in the pathophysiology of airway diseases [3, 4]. The concentration of exhaled NO is increased in patients with airway inflammation such as asthma [5-7] and bronchiectasis [8]. Exhaled NO concentration measured at the mouth, provided that the nasal NO does not contaminate the exhalate, is identical to that measured directly via bronchoscope in the trachea and in the lung, confirming its lower airway origin in normal and asthmatic subjects $[9,10]$.

The measurement of exhaled NO has excited considerable interest, as it may provide a simple noninvasive means for measuring airway or pulmonary inflammation [5, 6, 11-13]. There is now persuasive evidence that levels of NO are decreased by anti-inflammatory treatments, and this may be useful for monitoring whether treatment is adequate $[10,14,15]$.

The great advantage of exhaled NO is that the measurement is completely noninvasive and can, therefore, be performed repeatedly, and can be used in children and patients with severe airflow obstruction, where more invasive techniques are not possible $[14,16,17]$.

Exhaled NO may be useful in differential diagnosis since, in contrast to asthma, exhaled NO is not increased in chronic obstructive pulmonary disease (COPD) [18, $19]$, and is reduced in cystic fibrosis [14, 16, 20], and in patients with systemic sclerosis with pulmonary hypertension [21].

High concentrations can also be detected in nasal air of normal subjects [5, 10, 13, 22-24]. The paranasal sinuses appear to be large contributors to this NO, which

*Dept of Thoracic Medicine, National Heart and Lung Institute, Dovehouse Street, London, UK. **Dept of Physiology and Pharmacology, Karolinska Institute, Stockholm, Sweden.

Correspondence. P.J. Barnes, Dept of Thoracic Medicine, National Heart and Lung Institute, Dovehouse Street, London SW3 6LY, UK.

Received: April 3 1997; accepted for publication April 251997

This document was prepared following a Satellite Meeting of the European Respiratory Society Annual Scientific Meeting, held in Stockholm on 9 September, 1996, and attended by members of the ERS Taskforce on Measurement of Mediators in Exhaled Air (Chairman: Professor P.J. Barnes). Participants of the ERS Special Task Force Meeting "Measurement of Nitric Oxide in Exhaled Air" 9 September 1996, Stockholm: K. Alving (Stockholm, Sweden), P.J. Barnes (London, UK), J. Barbera (Barcelona, Spain), E. Baraldi (Padova, Italy), T. Dinh-Xuan (Paris, France), C.G. Frostell (Danderyd, Sweden); H.W.F.M. de Gouw (Leiden, The Netherlands), L. Gustafsson (Stockholm, Sweden), G. Hedenstierna (Uppsala, Sweden), T.W. Higenbottam (Sheffield, UK), M. Högman (Uppsala, Sweden), Q. Jobsis (Rotterdam, The Netherlands), J. De Jongste (Rotterdam, The Netherlands), H.A.M. Kerstjens (Groningen, The Netherlands), S.A. Kharitonov (London, UK), J. Kips (Ghent, Belgium), J.M. Lundberg (Stockholm, Sweden), J. Lundberg (Stockholm, Sweden), T.W. van der Mark (The Netherlands), N. Neuparth (Lisbon, Portugal), P.J. Sterk (Leiden, The Netherlands), P. Silkoff (Toronto, Canada), A. Sovijarvi (Helsinki, Finland), E. Weitzberg (Stockholm, Sweden). 
is constitutively produced by steroid-resistant nitric oxide synthase (NOS) $[25,26]$, but not by nasal commensal bacteria, as there is no reduction in nasal NO after antibiotics [24, 27]. Expression of NOS in normal human nasal mucosa $[24,25]$ and upregulation of inducible NOS (iNOS) in perennial allergic rhinitis, however, might be the reason for the reduction in nasal $\mathrm{NO}$ after treatment with nasal glucocorticosteroids in normal subjects and patients with allergic rhinitis $[24,28]$. By contrast, nasal NO levels are low in cystic fibrosis [14, 16, 20] and Kartagener's syndrome [27], and this might be accountable for chronic infection in the upper airways of these patients.

Several laboratories in Europe and the USA have reported measurements of exhaled and nasal NO using chemiluminescence, but the values recorded differ widely between them, reflecting differences in technological and/or measurement techniques. Therefore, there is a need to standardize the measurement if this approach is to be widely applied and comparison of results from different laboratories is to be possible. Although some data are available on nasal NO measurements, further investigation from a wider range of laboratories might be required before a detailed standardization of nasal NO measurements can be made. Therefore, we expect to update the recommendations as more detailed studies become available.

\section{Chemiluminescence analysers and general equipment}

\subsection{System design}

The equipment used in clinical investigation of exhaled NO varies widely in complexity, but all systems are based on the principle of the chemiluminescence method: NO in the sample air reacts with ozone, producing a defined amount of energized $\mathrm{NO}_{2}{ }^{*}$, which returns to its basic energy level by emitting a photon; the quantity of light is proportional to the NO concentration [29, 30].

\subsection{Equipment requirements}

Minimum standards for equipment are described in table 1. The following recommendations are made:

1. The accuracy of the analyser is important, especially in the assessment of low values of exhaled NO. Linearity should be $\leq 1 \%$. The analyser should be stable, so that linearity is maintained over the test period. The repeatability of the test should be within the coefficient of variation $\leq 10 \%$.

2. The analyser (fig. 1) should be equipped with mouthpiece tubing (A), connected to a side-arm sampling tube (B), made of an inert material (Teflon/polytetrafluoroethylene (PTFE)) and connected to a chemiluminescence analyser (C). The mouthpiece should have an internal restrictor (D) in the breathing circuit to allow exhalation with a low positive pressure 5-20 $\mathrm{cmH}_{2} \mathrm{O}$. The back-pressure created by expiration against this resistance (as low as $5 \mathrm{cmH}_{2} \mathrm{O}$ ) is already sufficient to keep the soft palate closed [31], so that the nasal cavities are partitioned from the remainder of the respiratory tract, preventing the contamination of exhaled air with nasal NO. As it is difficult for some subjects to maintain

Table 1. - Equipment specifications

\section{NO module}

Measurement unit

Accuracy

Lower detectable limit

Response time

Measurement range

Sample gas flow

Flow rate, pressure, volume module

Pressure/flow sensors to mea- Flow measurement range sure expiration flow, pressure, $0 \pm 1 \mathrm{~L} \cdot \mathrm{s}^{-1}$; (response and exhaled volume in real- time $\sim 25 \mathrm{~ms}$ ); pressure time. Control unit integrated measurement range into the analyser and equipped $0 \pm 25 \mathrm{cmH}_{2} \mathrm{O}$ (response with bio-feedback display time $\sim 25 \mathrm{~ms}$ ). designed to provide visual guidance for the subject to maintain the pressure and exhalation flow within a certain range, to improve test repeatability and to enhance patient co-operation.

$\mathrm{CO}_{2}$ module $\mathrm{CO}_{2}$ analyser (desirable but not obligatory).

\section{Calibration gas}

Calibration NO gas

Computer, software, recorder Computer with a printer or multichannel paper recorder (desirable).

Range 0-10\% $\mathrm{CO}_{2}$; resolution $\pm 0.1 \%$; response time $0.3 \mathrm{~s}$.

\section{Certified concentration (preferentially of $100 \mathrm{ppb}$ for exhaled NO measurements and $400 \mathrm{ppb}$ for nasal $\mathrm{NO}$ measurements) of $\mathrm{NO}$ balanced $\mathrm{N}_{2}$.}

The results of the analyses should be graphically displayed on a plot of NO concentration, pressure and flow against time. Plotting of $\mathrm{CO}_{2}$ and exhaled volume are optional.

the steady-state exhalation with a low exhalation pressure $\left(5 \mathrm{cmH}_{2} \mathrm{O}\right)$, a wider range has been recommended. However, the pressure should not be higher than 20 $\mathrm{cmH}_{2} \mathrm{O}$, as it might be uncomfortable for a patient and might elicit an increase in local NO release [32].

For exhaled NO measurements, subjects should exhale slowly from total lung capacity (TLC) (a complete vital capacity (VC) exhalation is not required) over 5-30 s (exhalation time depends on the response time of the analyser) with a flow of $5-15 \mathrm{~L} \cdot \mathrm{min}^{-1}$, against a low resistance $\left(5-20 \mathrm{cmH}_{2} \mathrm{O}\right)$ which is acceptable to most subjects. 3. NO should be sampled for analysis via a Teflon/PTFE tubing side-arm attached to the mouthpiece to prevent loss of NO.

4. Oral pressure and exhalation flow should be measured in the breathing circuit (E) (fig. 1). Ideally, the 


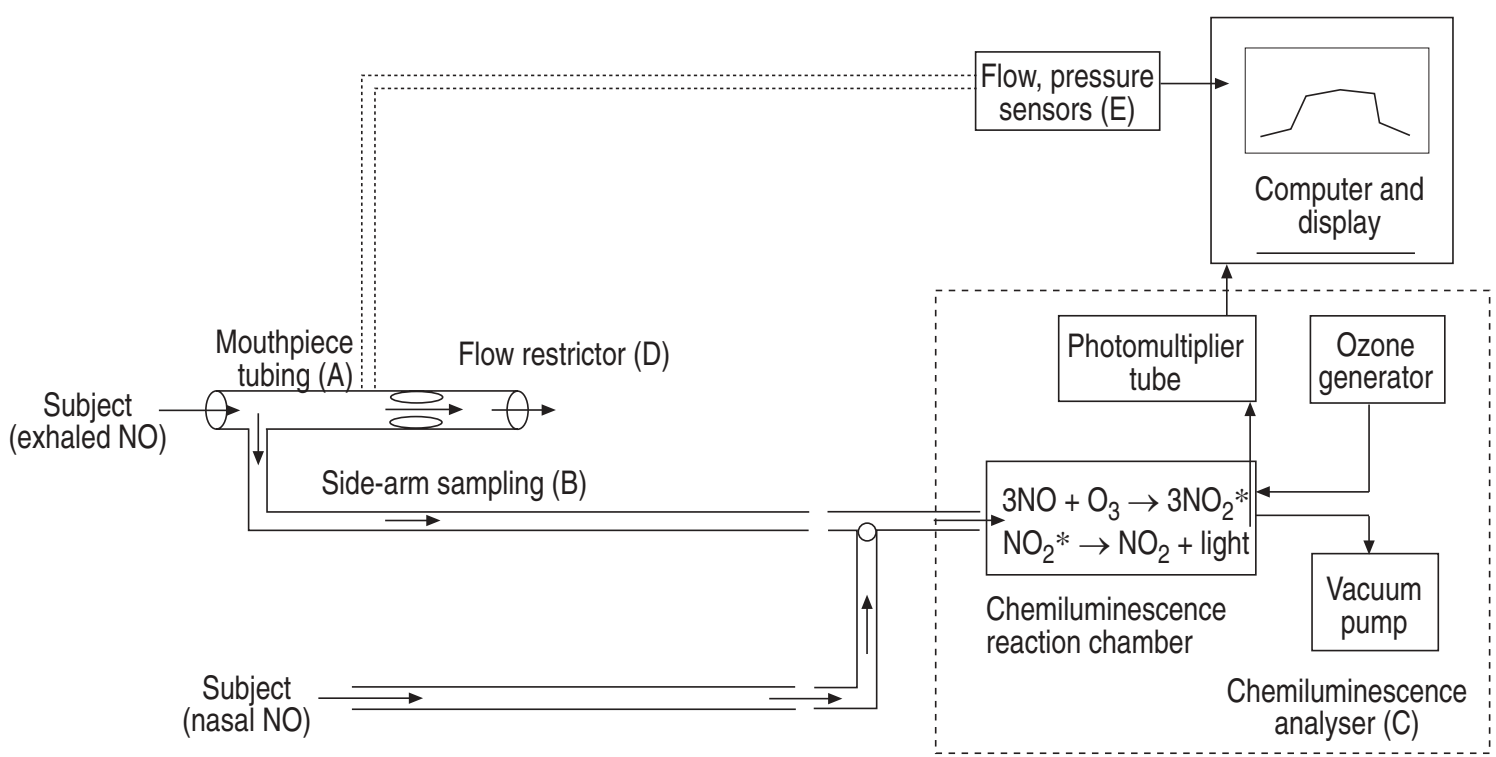

Fig 1. - Schematic illustration of exhaled nitric oxide (NO) measurements for the single slow exhalation against a resistance, and nasal NO measurements for the direct nasal sampling.

unit should be equipped with bio-feedback oral pressure and/or an exhalation flow display, designed to provide visual guidance for the subject to maintain the pressure and/or exhalation flow within the desired range, thus improving test repeatability and enhancing patient cooperation. Alternatively, there are simple means of standardizing expiratory flow, using a calibrated mechanical external choke system, which can simply maintain expiratory flow at any desirable level.

5. Simultaneous measurements of $\mathrm{CO}_{2}$ may be useful in demonstrating what part of exhalation is analysed.

6 . The analyser should be connected to a computer to allow the parameters measured, $\mathrm{NO}$, flow and pressure (and $\mathrm{CO}_{2}$ if available), to be simultaneously displayed against time (fig. 2). It is desirable to integrate all asso-
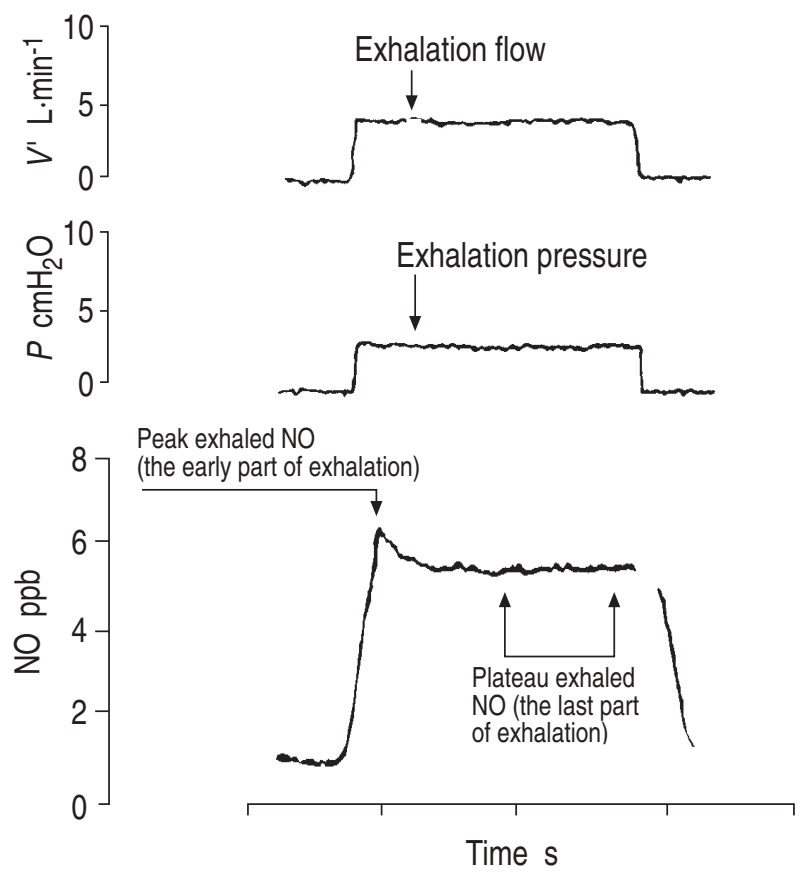

Fig. 2. - Schematic illustration of exhaled nitric oxide (NO) measurements. $P$ : pressure; $V^{\prime}$ : flow. ciated instrumentation and computing within a single system. The software should allow the investigator to choose a suitable plateau of NO concentration or flow rate for calculation of the NO release rate. The analysis of the signal should be expressed as a concentration (parts per billion (ppb)) for peak and plateau NO values, or as a release rate in $\mathrm{pmol} \cdot \mathrm{s}^{-1}$ (at standardized flow).

\subsection{Quality control}

Minimum standards for equipment quality control are described in table 2 . The analyser should have a rapid response time for a peak $\mathrm{NO}$ detection $(0.02 \mathrm{~s}$ is feasible). However, for plateau NO measurements, a response time of $<2 \mathrm{~s}$ is acceptable.

The response time of the analyser may be determined by piercing a balloon filled with the NO calibration gas and connected to the sampling port of the analyser. The square wave change in NO over time will give the response time of the analyser.

The following procedures are recommended:

1. Before each NO measurement: perform NO zeroing. Manufacturers are encouraged to provide hardware and software for automatic NO zeroing before each NO measurement, using NO-free air or other means.

2. Daily: a) test for leaks in the system; and b) change bacteriological and system protection filters. A normal

Table 2. - Equipment quality control

\begin{tabular}{ll}
\hline Nitric oxide (NO) zero calibration & Before each test \\
Visual test of breathing and & Tested daily \\
sampling circuits & \\
Bacteriologist and system protection & Changed daily \\
filters & \\
$\begin{array}{l}\text { Tests on laboratory personnel } \\
\text { (standard subject) }\end{array}$ & Tested daily \\
NO calibration & Tested every 2-3 days \\
Flow and pressure zero calibration & Tested weekly \\
CO calibration & Tested quarterly \\
Flow, volume and pressure & Tested quarterly \\
calibration & \\
Chemiluminescence linearity & Tested quarterly \\
\hline
\end{tabular}


subject(s) could be tested to assure overall stability of the system. Normal subjects are healthy nonsmokers (e.g. healthy laboratory personnel). When sufficient data on a standard individual are obtained, laboratories may choose to establish their own criteria to serve as indicators of potential problems with their NO analyser.

3. Every 2-3 days: perform two-point calibration, providing there is an automatic NO zeroing procedure before each measurement, using a certified concentration (preferably $100 \mathrm{ppb}$ for exhaled NO measurements and $400 \mathrm{ppb}$ for nasal NO measurements) of NO balanced with $\mathrm{N}_{2}\left(\mathrm{NO} / \mathrm{N}_{2}\right)$.

It is important that total $\mathrm{NO}_{\mathrm{x}}$ within the cylinder does not exceed the values of the NO itself by more than 10 ppb. High values of $\mathrm{NO}_{x}$ are an indication of instability of the calibration gas and the possibility of its rapid deterioration.

Calibration gas may be obtained from BOC Gases, which has the technology (Spectra-Seal) for passivating aluminium cylinders containing reactive gas mixtures, in order to obtain stable NO standards at low concentrations. There are now full production quantities of 100 and $400 \mathrm{ppb} \mathrm{NO} / \mathrm{N}_{2}$ calibration gases in $10 \mathrm{~L} 150 \mathrm{bar}$ cylinders, with either BS14 UK or DIN14 continental valve outlets (The Priestley Centre, Guildford, Surrey, UK). These mixtures are supplied as Spectra-Seal branded mixtures, with guaranteed stability for 5 yrs. BOC Gases currently has further standards undergoing analysis, including third party validation by the National Physical Laboratory for independent analysis over a 6 month period, which are at just $50 \mathrm{ppb}$. Certified calibration gas may also be obtained from AGA AB (Lidingö, Stockholm, Sweden). However, if the certified low grade NO calibration gas cylinders are not available, a high concentration of $\mathrm{NO} / \mathrm{N}_{2}(1-100$ parts per million (ppm)) might be used when diluted by precision electromagnetic flow controllers.

4. Weekly: if $\mathrm{CO}_{2}$ is analysed, perform calibration using a certified concentration $(5 \%)$ of $\mathrm{CO}_{2}$. Calibration gas may be obtained from BOC, Special Gases, UK, or from BOC, Special Gases, Zaventem, Belgium.

5. Each quarter: perform two-points flow and pressure calibration with a calibrated $1-5 \mathrm{~L}$ syringe.

\subsection{Infection control}

It is important to prevent transmission of infection to subjects and staff during exhaled and nasal NO measurements. The following recommendations are made: 1. Standard procedures and recommendation on hygiene and infection control have been formulated in "Standardization of Spirometry" (American Thoracic Society (ATS), 1994) [33], and may be applied to NO measurements. 2 . In settings where routine disassembly of the tubings is not possible, in-line filters may be effective in preventing contamination of equipment [33]. If an in-line filter is used, the measuring system must meet the minimal recommendations listed above for system accuracy, and flow resistance and equipment must be calibrated with a filter installed.

3. The use of a disinfectant containing alcohol (e.g. chlorhexidine $0.5 \%$ in $70 \%$ ethanol) should be avoided immediately before the tests, as NO measurements might be augmented by ethane, which is a product of the disintegration of ethanol and is a known source of interference in chemiluminescence measurement [34].

4. Manufacturers of $\mathrm{NO}$ equipment are encouraged to design instrumentation that can be easily disassembled for disinfection, or find other solutions to hygiene concerns.

\section{Exhaled NO: standardization issues}

\subsection{Inspiratory and ambient $N O$}

Inhaling NO-free air during NO measurements is the most standardized method of NO assessment in the laboratory setting, or under some specific climatic conditions (cold weather). In Finland, for instance, during winter, ambient NO has been shown to vary between 1-2 and $600 \mathrm{ppb}$ (A. Sovijärvi, Helsinki University Central Hospital, Finland, personal communication).

However, in the field, no relationship has been found between ambient and exhaled NO levels [6, 9, 17, 18, $35,36]$ in normal or asthmatic subjects. It has also been shown that inhalation of the NO calibration gas (113$800 \mathrm{ppb}$ ) does not affect the peak exhaled NO in normal subjects $[6,18]$. This may be related to the fact that NO rapidly combines with haemoglobin [36, 37], and is swiftly taken up by the lungs when inhaled. Thus, a breathhold of $7.5 \mathrm{~s}$ reduced the concentration of inhaled NO from 40 to $3 \mathrm{ppm}$, with a further reduction of up to $1 \mathrm{ppm}$ NO following 9-11 s of breathhold [36]. Provided that exhaled NO is measured at the end of a slow (5-30 s) single exhalation manoeuvre, after inspiration of ambient air that is very unlikely to be higher than 1 ppm NO, the influence of ambient NO on exhaled NO is likely to be negligible.

However, the possibility exists that exhaled NO measured in the air collected during tidal breathing, when the dead space contribution is enlarged, may be contaminated with ambient NO.

High ambient NO may contaminate nasal NO when measured by direct sampling from the nose, as the nasal cavities cannot absorb ambient NO to the same extent as the lungs. However, since the normal range for nasal NO is $900-1,000 \mathrm{ppb}$, the concentration of ambient NO would need to be $>90 \mathrm{ppb}$ to be sufficient to increase NO readings by $10 \%$.

It is recommended that the ambient NO level is always recorded. An environmental source of NO can be excluded as a contributory factor to exhaled NO measured during slow exhalation against a low resistance when nasal cavities are separated from the remainder of the respiratory tract, when almost all the inhaled NO will be absorbed in the lungs or exhaled with the dead space volume. NO-free air (Medical Air, nominal oxygen content $21 \%$ ) should be used when ambient NO levels are high $(>40 \mathrm{ppb})$.

Furthermore, NO-free air should always be used when a mixed exhaled air is collected during tidal breathing, unless the NO concentration of ambient air is negligible, or when nasal NO is measured during direct nasal sampling when ambient NO levels are high $(>40$ ppb). 


\subsection{Procedural sources of variation in NO measurements}

3.2.1 Patient-related factors. Conditions that may affect exhaled and nasal NO release (table 3 ) should be avoided, or registered and used for the interpretation of the data. There are, as yet, no data available to demonstrate any change in NO measured with subjects from the seated to the supine position. However, most studies have been performed with NO measured whilst the subject is in the seated position, and, therefore, this is recommended as a standard position for spontaneously breathing subjects.

Before beginning the test, it is recommended that the manoeuvres are demonstrated and the subject carefully instructed. The subject should be seated for at least 5 min before testing, and should remain seated throughout the procedure. The test should be performed with the subject having refrained from recent strenuous exercise.

Table 3. - Processes and factors affecting exhaled and nasal nitric oxide (NO)

Increased NO Decreased NO

\section{Exhaled NO}

Technical factors

Low exhalation flow rate High exhalation flow rate

Breathholding

NO modulators

Ingested L-arginine in normal subjects

Inhaled or i.v. NOS inhibitors (L-NMMA, L-NAME, aminoguanidine, etc.) Inhaled or oral glucocorticosteroids

Physiological factors

Menstrual cycle variations Menstrual cycle variations

Breathholding

Physical exercise

Diseases

Asthma

Allergen challenge

(late response)

Upper respiratory tract

infection

Lower respiratory tract

infection

Bronchiectasis

Cirrhotic patients with

hepatopulmonary syndrome

Nasal NO

Technical factors

Low sampling flow rate High sampling flow rate

NO modulators

i.v. L-arginine in normal Nasal glucocorticosteroids in subjects

Physiological factors

Breathholding or nose occlusion

Diseases

Allergic rhinitis

Smoking

Acute alcohol ingestion

Systemic sclerosis with

pulmonary hypertension

Cystic fibrosis

COPD normal subjects and patients with seasonal allergic rhinitis

Nasal decongestants $(\alpha$-adrenergic agonists)

Intranasally or intrasinusally administered NOS inhibitor L-NAME

Physical exercise
Kartagener's syndrome
Cystic fibrosis
Primary ciliary dyskinesia

NOS: nitric oxide synthase; L-NMMA: $\mathrm{NG}^{\mathrm{G}}$-monomethyl-L-arginine; L-NAME: $\mathrm{N}^{\mathrm{G}}$-nitro-L-arginine methyl ester; COPD: chronic obstructive pulmonary disease.
3.2.2 Inspiratory manoeuvre. The NO manoeuvre begins with exhalation to residual volume (RV) followed by rapid inhalation to TLC. In healthy subjects, inspiratory time averages $1.5-2 \mathrm{~s}$, and in patients with severe airflow obstruction (forced expiratory volume in one second $(\mathrm{FEV} 1) / \mathrm{VC}<0.5)$, inspiratory times average about $4 \mathrm{~s}$ [38].

It is recommended that the inspiration is rapid (no longer than $2.5 \mathrm{~s}$ in healthy subjects and $4 \mathrm{~s}$ in patients with severe airway obstruction).

3.2.3 Exhalation parameters: pressure, flow and volume. Exhaled and nasal NO are markedly flow-dependent, and a significant reduction in NO concentrations has been reported when sampling or exhalation flow rates increase $[5,10,13,31,39,40]$. The probable reason for the reduction in NO concentration with increased expiratory or sampling flow is that the same amount of NO will be dispersed in a different exhaled or sample volume. Thus, with a higher exhalation or sampling flow, NO will be diluted in a greater volume and, hence, a lower NO concentration will be detected.

There is no apparent influence of exhaled volume on NO levels, providing dead space volume is discarded. In a single exhalation, exhaled $\mathrm{NO}$ almost reaches a plateau after 5-10 s of exhalation, whilst the $\mathrm{CO}_{2}$ and exhaled volume continue to increase [10]. There is no difference in NO concentration between mixed expired air collected into a reservoir after a full VC exhalation and an exhalation from one tidal breath above functional residual capacity (FRC) to RV either in normal or asthmatic subjects $[9,19]$.

Fractional analysis of expired gas, collected during exhalation against a low resistance, has also shown no significant difference in exhaled $\mathrm{NO}$ between the first $40-45 \%$ (mean \pm SEM $\left.6.9 \pm 1.9 \mathrm{ng} \cdot \mathrm{L}^{-1}\right)$ and the remaining part $\left(5.1 \pm 1.0 \mathrm{ng} \cdot \mathrm{L}^{-1}\right)$ of an exhalation [41]. However, the first exhalation fraction is usually associated with a transient NO peak (fig. 2), which represents the portion of exhaled air most contaminated with the nasal [40, 42], oropharyngeal and ambient NO in the dead space. The detection of this peak depends on the response time of the analyser, and should be discarded from the analysis, unless there is a particular need to analyse NO in this part of exhalation.

It is recommended that the exhalation is slow (5-30 s), from TLC or close to TLC with an exhalation flow rate of $10-15 \mathrm{~L} \cdot \mathrm{min}^{-1}$, and against a low resistance (5-20 $\mathrm{cmH}_{2} \mathrm{O}$ ). The flow rate should be kept as constant as possible and measured during the manoeuvre. There is no need to empty the whole VC.

3.2.4 Expiratory manoeuvre. As the release of NO from the nasal passages is approximately 40-120 times that of the rest of the respiratory tract $[10,23,42,43]$, it is crucial to separate the nasal passages from the remainder of the respiratory tract during an exhalation manoeuvre, hence preventing the contamination of exhaled NO with nasal NO.

There are three main approaches to measurement of exhaled NO: 1) single slow exhalation through the mouthpiece, with side-arm sampling or passage directly into the analyser; 2) collection of the exhaled air into a reservoir during tidal breathing or single exhalation, with analysis thereafter; and 3) sampling from a mixing chamber at the expiratory side of the mouthpiece during tidal 
breathing or via a side-arm from the mouthpiece, until steady-state levels are achieved.

It has been shown that the nasal contribution to mouth breathing can be effectively eliminated by voluntary soft palate closure or by applying the balloon occlusion method [35], or just by exhaling against a resistance [10, 39].

Using the exhalation against a resistance technique as the simplest but most effective method, several groups have obtained exhaled NO values that are in good agreement, giving mean $( \pm$ SEM) values of: $8 \pm 0.8 \mathrm{ppb}[1] ; 7 \pm 4$ ppb [35]; $7 \pm 1 \mathrm{ppb}[10]$; and $6 \pm 0.4 \mathrm{ppb}$, even though the latter was analysed from a reservoir [17]. Indeed, there was no difference in exhaled NO measured either during slow exhalation against resistance $(7 \pm 4 \mathrm{ppb})$ or after the nasopharynx was isolated by inflated balloon occlusion $(7 \pm 4 \mathrm{ppb})$ [35].

Recently, it has been shown that a single slow exhalation against a low resistance may be successfully applied in normal children and in children with cystic fibrosis aged 6-17 yrs [16].

The reservoir collection method is the other option for NO release measurements at rest or during exercise, when the chemiluminescence analyser is not available on site, or in children or adults who are unable to maintain steady-state exhalation during a slow exhalation manoeuvre. Thus, during a single VC exhalation into the reservoir when the first contaminated portion of the air was discarded, the mean $( \pm$ SEM) NO levels in the remaining part of the exhaled air were in good agreement: $8.1 \pm 3.3 \mathrm{ppb}$ [36], and $8.4 \pm 1.2 \mathrm{ppb}$ [9]. Inert material, such as polyethylene or NO-impermeable Mylar, should be used for collection [9, 35, 44, 45].

However, there is convincing evidence for a substantial nasal contribution to the exhalate during tidal breathing or a single breath without resistance because of soft palate opening [46], which might explain the higher NO values of 14-18 ppb when measured during tidal breathing through the mouth $[35,37,45]$, in comparison with a single exhalation against a low resistance into a reservoir, 6.2 $\pm 0.4 \mathrm{ppb}[17]$.

Therefore, NO measured in exhaled air collected during tidal breathing into a reservoir is more likely to represent a mixed exhaled $\mathrm{NO}+$ nasal NO, unless there is a low resistance to each exhalation, and this may diminish any changes that might occur in NO derived from the lower respiratory tract.

Sampling from a mixing chamber at the expiratory side of the mouthpiece during tidal breathing or via a side-arm from the mouthpiece until steady-state levels are achieved, has recently been applied in normal and asthmatic children and children with cystic fibrosis aged 5-15 yrs [14, 16, 20].

It is recommended that an appropriate selection of inert mouthpiece tubings and reservoir materials is made. Rubber that contains sulphydryl groups and may react with NO must not be used. Attention should be given to leaks or malfunctioning valves and tube fittings.

1. In adults and in children (from the age of 6 yrs), slow exhalation from TLC through the mouthpiece against a low resistance is preferable. For this measurement of exhaled NO, subjects should be asked, after the inspiration, to exhale slowly and steadily from TLC over 5$30 \mathrm{~s}$, with a target exhalation flow rate $\left(10-15 \mathrm{~L} \cdot \mathrm{min}^{-1}\right)$, through the mouthpiece tubing and with an internal restrictor in the breathing circuit to allow for exhalation with a low resistance, 5-20 $\mathrm{cmH}_{2} \mathrm{O}$. Expired air is sampled via a side-arm tubing directly into the analyser for NO measurements. Noseclips should not be worn.

During expiration, the first wash-out volume of expired gas $(0.75 \mathrm{~L})$, representing the anatomical and mechanical dead space [47] and contaminated with nasal and ambient NO, and therefore associated with a peak in NO values during the early part of exhalation (fig. 2), must not be used for assessments of lower airway NO. If the VC is $<2 \mathrm{~L}$, the wash-out volume may be reduced to $0.5 \mathrm{~L}$.

The plateau level of the last part of exhalation should be taken (fig. 2). These values of exhaled NO, corresponding to the plateau of end-exhaled $\mathrm{CO}_{2}$, reading $\left(5-6 \% \mathrm{CO}_{2}\right)$ have been identified as representing the lower respiratory tract samples by direct sampling from the lower airways via a bronchoscope $[9,10]$. The plateau NO readings also have the advantage of being independent of the inhalation route, via the nose or mouth [31], as the first part of exhalation, contaminated with nasal NO, can be ignored.

For the same reason, exhaled air collected into a reservoir, will inevitably contain a mixture of exhaled and nasal air, unless a system of valves (made of inert material) and electrical triggers is applied to separate the last part of expiration and this will increase the cost and complexity of the procedure.

2 . In children younger than 5 yrs and infants, or in adults who are unable to maintain steady-state exhalation during a slow exhalation manoeuvre, the tidal breathing method with or without consequent reservoir collection, standardized by expiratory flow, volume and time of the collection is the measurement of choice.

3. Another option for NO measurements in children is "a balloon technique", successfully used in Sophia Children's Hospital, University Hospital, Rotterdam by R. Jöbsis and J. de Jongste (personal communication), where exhaled NO can be measured using Mylar (NO-impermeable material) balloons. Balloon filling requires some positive pressure, hence preventing contamination with nasal NO, and can be standardized. Children are asked to take a deep breath and inflate the balloon via a mouthpiece of a certain diameter in one breath. Two or three balloons may be inflated for duplicate or triplicate measurements. The balloon will be then sealed and brought to the analyser, and NO will be measured by breaking the seal and sampling air directly from the balloon.

Comparisons between these methods are needed.

3.3 Interval between measurements. It is generally recognized that $2-3$ breaths would eliminate any excess of NO accumulated during 5-30 s of exhalation. It is reasonable to expect that an interval of at least $1 \mathrm{~min}$ between tests may be sufficient in normal subjects and even in patients with severe maldistribution of ventilation.

It is recommended that an interval of $1 \mathrm{~min}$ for normal subjects and at least 2 min for patients with severe maldistribution of ventilation should be allowed between tests to allow adequate elimination of NO between the manoeuvres.

The subject should remain seated during this interval. In patients with obstructive airway disease, several deep inspirations during this period may help to ventilate the lungs. 


\section{Nasal NO measurements}

There are two main approaches to nasal NO assessment: 1) use of a NO-free air stream infused into one nostril at a certain flow rate and exiting from the other nostril, where it is analysed, during mouth breathing or breathholding; and 2) direct sampling from the nose with an airstream generated by the analyser, whilst mouth or nasal breathing or breathholding.

Nasal NO measurements are also flow-dependent [40], and the importance of the dilution of nasal NO with the air from the lower airways cannot be overestimated. Thus, mean (士SEM) nasal NO levels in healthy children when sampled from the nose during tidal breathing through the mouth were $239 \pm 20 \mathrm{ppb}$, and were only $21 \pm 9.1 \mathrm{ppb}$ during tidal nasal breathing [14]. High nasal levels of NO have been detected during direct binasal sampling (394 $\pm 23 \mathrm{ppb})$ whilst mouth breathing and via a bronchoscope directly from the nasopharynx $(334 \pm 52$ $\mathrm{ppb}$ ), but were increased up to $\geq 1,000 \mathrm{ppb}$ during breathholding when the soft palate was closed [42], or up to $1.5 \pm 0.2 \mathrm{ppm}$ after the nasal cavities were occluded for $120 \mathrm{~s}$ [48]. The use of an airstream of 2-5 L $\cdot \mathrm{min}^{-1}$ through the nose, reduced nasal NO levels down to $105 \mathrm{ppb}$ during mouth breathing and $140 \mathrm{ppb}$ whilst breathholding [5]. Direct nasal sampling during breathholding with a closed soft palate gave nasal NO values of $270 \pm 37 \mathrm{ppb}$ [27] at a flow rate of $700 \mathrm{~mL} \cdot \mathrm{min}^{-1}$ and $996 \pm 39 \mathrm{ppb}$ [10] at a flow rate of $250 \mathrm{~mL} \cdot \mathrm{min}^{-1}$.

Recent publications have shown that direct nasal NO sampling during breathholding in adults $[10,26]$ and children $[14,16]$ may be a preferential technique, as breathholding keeps the soft palate closed [35], hence preventing mixing of nasal NO with lower airways NO. Soft palate closure has been confirmed by the absence of an increase in $\mathrm{CO}_{2}$ during sampling, even though there is a low $(\leq 1 \%)$ plateau $\mathrm{CO}_{2}$ level representing a residual $\mathrm{CO}_{2}$ coming out of the sinuses [10].

It is recommended that nasal NO be measured with a probe inserted into one of the nares, whilst the subject breathholds, i.e. with no active exhalation. Subjects should be relaxed during a breathholding manoeuvre and maintain a full inspiratory position, with the mouth closed without straining. Closure of the soft palate will allow analysis of the local NO concentration, with free flow of ambient air or NO-free air from one nostril to the other and subsequent direction into the analyser. The value of the last plateau part of the trace of nasal NO should be recorded (fig. 3 ).

The optional monitoring of $\mathrm{CO}_{2}$ levels in the nasal gas sampled might be the simplest and most effective

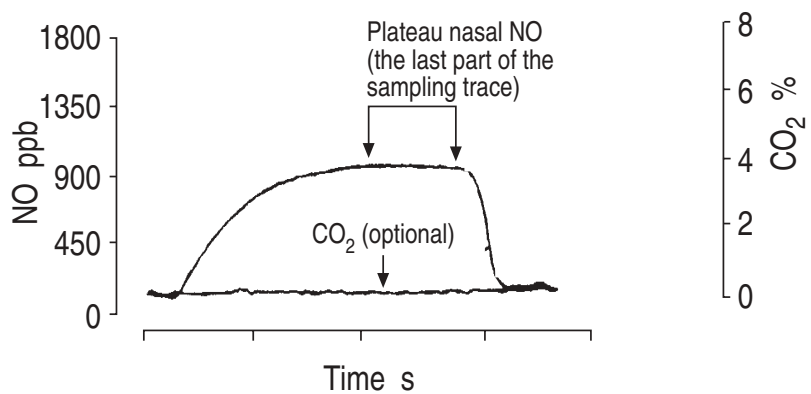

Fig. 3. - Schematic illustration of nasal nitric oxide (NO) measurement. ppb: parts per billion. way to confirm closure of the soft palate, hence improving reproducibility of the test.

The use of nasal decongestants should be avoided prior to measurements, since these have been shown to acutely reduce nasal NO concentrations [49].

\section{Factors influencing NO measurements}

\subsection{Height, weight, age and sex}

Although no relationship has recently been found between size and exhaled NO measured in the trunk of Asian elephants [50], human data are rather more conflicting. No significant correlation has been reported between body weight or body surface and exhaled NO levels in either sex [51]. However, in a preliminary study of 36 subjects aged 20-64 yrs, a significant correlation was found between exhaled NO, expressed as NO release per square metre of body surface area $\left(\mathrm{nl} \cdot \mathrm{min}^{-1} \cdot \mathrm{m}^{-2}\right)$, and body surface area [52]. Although, it was observed that there was a $30 \%$ increase in peak nasal NO levels measured after the sampling gas flow was stopped for 120 $\mathrm{s}$, between 1 and $24 \mathrm{~h}$ of age, in 13 healthy newborn infants [48], there are so far no published data available concerning age effects on normal NO values in adults and children. It has been reported that higher levels of exhaled NO in males measured on one occasion (median $34 \mathrm{ppb}, 95 \%$ confidence intervals (95\% CI) 31-58 ppb), compared with females measured on three occasions during the menstrual cycle (median $20 \mathrm{ppb}$, 95\% CI 16-32 ppb) [51]; however, studies of better design are needed to specifically address this question.

\subsection{Water vapour}

Water vapour and $\mathrm{CO}_{2}$ might quench the chemiluminescence measurements $[53,54]$, but their influence in respiratory concentrations has not yet been sufficiently studied. There is evidence, however, that saturation with water vapour leads to a systematic underestimation of exhaled NO levels, but the influence of $\mathrm{CO}_{2}$ in the respiratory range is negligible (T.W. van der Mark, 1996, personal communication). More research is needed in this area.

\subsection{Physical exercise}

In normal subjects, exercise caused a nonsignificant increase in exhaled NO, measured by the single-breath technique, whereas voluntary hyperventilation caused a reduction or no change in exhaled NO levels [55], but increased $\mathrm{NO}$ in the mixing chamber at the expiratory side of a T-valve [56]. However, when expressed as rate of NO release ( $\mathrm{pmol} \cdot \mathrm{min}^{-1} \cdot \mathrm{kg}^{-1}$ ), a reversible significant increase in exhaled NO was found during exercise, correlating with the heart rate but not with the respiratory changes. Recently, increased exhaled NO output during exercise was found to be more closely related to increased ventilation than to increased blood flow [52]; and nasal NO-release was reduced by acute physical exercise $[40,57]$. Therefore, physical exercise might modulate the release of $\mathrm{NO}$ from the respiratory tract, but 
the mechanisms of these reversible changes, as well as a technique for NO measurements during exercise, require further investigation.

\subsection{Respiratory pattern}

A specially designed sampling device has been used during tidal breathing in normal subjects to monitor the concentration of NO separately in the initially exhaled $200 \mathrm{~mL}$ fraction of exhaled air $\left(F_{1}\right)$, representing more gas derived from airways, after dead-space volume was discarded, and in the remainder of exhaled air $\left(F_{2}\right)$, representing more alveolar gas [58]. The concentration of NO in $F_{1}$ was consistently higher than in $F_{2}$, with or without intubation, suggesting the unique effect of respiratory pattern on the concentration of exhaled $\mathrm{NO}$, and that the NO concentration detected in exhaled air comes mainly from the airway rather than from the alveoli. Furthermore, the effect of the breathholding manoeuvre on the NO concentration of exhaled air was again significant only in $F_{1}$.

\subsection{Breathholding}

Breathholding increases NO in the exhaled air in normal and asthmatic subjects in a duration-dependent manner $[7,10,56,58]$. There was a strong correlation between the duration of breathholding and the peak of NO during the early phase of exhalation [56]. Breathholding also resulted in an initial peak of NO that was significantly higher in asthmatics than in normal subjects [10].

High nasal NO levels detected during direct binasal sampling whilst mouth breathing were increased from over $390 \mathrm{ppb}$ up to $\geq 1,000 \mathrm{ppb}$ during breathholding [42], or up to $1,500 \pm 2,000 \mathrm{ppb}$ after the nasal cavities had been occluded for $120 \mathrm{~s}$ [48].

\subsection{Cigarette smoking}

Cigarette smoking significantly reduces NO levels in expired air of normal subjects [7, 18, 23, 45, 59], and the reduction is related to the number of cigarettes currently smoked [59]. There is a chronic effect, reflected by a lower level of exhaled NO when subjects refrain from smoking for several hours, and an acute effect seen immediately after smoking a cigarette [59]. The reduction in exhaled NO may be due to downregulation in NOS caused by the high concentration of NO in cigarette smoke.

\subsection{Alcohol}

Ethanol has an inhibitory effect on iNOS [60], and therefore, perhaps, alcohol ingestion causes reduction of $\mathrm{NO}$ in exhaled air [61].

\subsection{Menstrual cycle and pregnancy}

Although the lowest exhaled NO values were observed just before and during the menses, a midcycle increase in exhaled NO has been reported [62], and may reflect cyclical hormonal changes in women. An increase in the plasma nitrite/nitrate concentration has been shown during the follicular phase of the cycle, and, in contrast, a reduction in the luteal phase has been noted, even in the presence of high oestradiol levels [63]. However, there was no increase in exhaled NO or urinary nitrate in the follicular phase of the cycle [64], and exhaled NO concentrations were not significantly altered during pregnancy [65].

\subsection{Upper respiratory tract infection}

Viral infection may induce the expression of iNOS [4], and elevation of NO in exhaled air of normal and asthmatic subjects with upper respiratory tract infections (URTI) have been found [66, 67]. Also, during episodes of lower respiratory tract viral infection, elevated exhaled NO levels have been reported [5], but so far the number of subjects studied to date is, perhaps, too small to make a definite statement.

\subsection{Diet and expelled air}

L-arginine, given orally or intravenously to normal subjects, increases exhaled [68] or nasal NO [26] in a dose-dependent manner, but it is unlikely, given our present knowledge, that normal dietary variation in L-arginine influences exhaled NO measurements, unless subjects are consuming substantial amounts of L-arginine from health food shops.

NO levels in air expelled (belching) during fasting were $602 \pm 107 \mathrm{ppb}$, and these levels increased fourfold 5 min after intake of lettuce [69].

The following recommendations are made:

1. Attention should be paid to the fact that water vapour might lower the NO levels measured. Periodic flushing of the tubing and the analyser's sampling system with dry air and/or the use of water absorbers, filters and/or heating elements are options. Manufacturers are encouraged to provide options for elimination of moisture, without affecting NO measurements.

2. Subjects should be asked about their smoking habit. 3. Subjects should avoid alcohol for at least $4 \mathrm{~h}$ before testing.

4. Females should be asked about their menstrual cycle. 5. NO measurements should not be reformed at the time of URTI or up to 4 weeks following.

6. Subjects should be asked about their diet, especially if they are taking food supplements containing L-arginine, or a nitrate-rich or nitrate-restricted diet.

7. The exhaled NO measurement should be discarded if the patient belches during the test as it might lead to incorrect results.

\section{Normal NO release in airways}

\subsection{Normal exhaled and nasal NO}

There seems to be no consistent effect of age or gender on exhaled NO from the lower respiratory tract, at least in adults, but further studies are needed in this area. 
Using the technique of slow exhalation against resistance, and similar exhalation and sampling flow rates, several groups have obtained mean $( \pm$ SEM) exhaled NO values in normal subjects that are in good agreement: $8 \pm 0.8 \mathrm{ppb}[1] ; 7 \pm 4 \mathrm{ppb}[35] ; 7 \pm 1 \mathrm{ppb}$ [10].

A single exhalation technique or direct nasal sampling can also be used in children aged $\geq 5$ yrs. Using a similar technique of slow exhalation against resistance and similar exhalation and sampling flow rates in children aged 5-17 yrs, exhaled NO values were 4.8 $\pm 1.2 \mathrm{ppb}$ $( \pm \mathrm{SD})$ [14] and $4.8 \mathrm{ppb}(95 \%$ CI 3.8-5.8) [16].

Nasal NO levels, measured with a probe inserted into one of the nares, whilst the subject was breathholding were $900-1,000 \mathrm{ppb}$ in normal adult subjects [10, 42], and $1,024 \mathrm{ppb}(95 \%$ CI 896-1,151 ppb) in healthy children aged 6-17 yrs [16].

Using the technique of a single exhalation into a reservoir, when the first contaminated part of exhaled air is discarded or when an exhalation was against a resistance, several groups have obtained exhaled NO levels in normal subjects that are also in good agreement: $8.1 \pm 3.3 \mathrm{ppb}$ [37] and $8.4 \pm 1.2$ [9].

Recently, a technique that allows analysis of different portions of exhaled air collected in a reservoir during tidal breathing in normal subjects found NO levels of $8.5 \pm 1.5 \mathrm{ppb}$ in the last portion of exhalation [58].

For younger children and infants it may be necessary to use a tidal breathing method, but nasal contamination may be a problem and further research is needed.

\subsection{Expression of $\mathrm{NO}$ values}

Most authors have expressed NO in ppb, derived from NO-peak or NO-plateau concentrations measured in a single exhalation or when it was sampled directly from the nose during breathhold.

However, NO values may also be expressed as release rate in $\mathrm{pmol} \cdot \mathrm{s}^{-1}$, Equation (1), or in $\mathrm{nL} \cdot \mathrm{min}^{-1}$, Equation (2):

$$
\begin{gathered}
{[\mathrm{NO}] \times Q^{\prime}{ }_{1}=\mathrm{pmol} \cdot \mathrm{L}^{-1} \cdot \mathrm{L} \cdot \mathrm{s}^{-1}=\mathrm{pmol} \cdot \mathrm{s}^{-1}} \\
{[\mathrm{NO}] \times Q^{\prime}{ }_{2}=\mathrm{ppb} \cdot \mathrm{L} \cdot \mathrm{min}^{-1}=} \\
10^{-9} \times \mathrm{L} \cdot \mathrm{min}^{-1}=\mathrm{nL} \cdot \mathrm{min}^{-1}
\end{gathered}
$$

where $[\mathrm{NO}]=\mathrm{NO}$ concentration in $\mathrm{ppb} ; Q^{{ }^{\prime}}{ }_{1}=$ exhalation flow in $\mathrm{L} \cdot \mathrm{s}^{-1} ; Q^{\prime}{ }_{2}=$ exhalation flow in $\mathrm{L} \cdot \mathrm{min}^{-1} ; 1 \mathrm{ppb}$ $\mathrm{NO}=40.908 \mathrm{pmol} \cdot \mathrm{L}^{-1}$ at normal temperature and pressure, or $1 \mathrm{ppb}$ NO gives $10^{-9}$ at ambient temperature and pressure saturated with water vapour (ATPS).

\section{Other inflammatory markers in exhaled air}

Some other volatile substances may also be detected in exhaled air. Thus, ethane and pentane (volatile products of lipid peroxidation) and hydrogen peroxide may be used to detect oxidant stress in the respiratory tract, and may also be useful as markers of inflammation [70-72]. There are also reports of measurements of lipid mediators (leukotriene $\mathrm{B}_{4}$ ) and cytokines (tumour necrosis factor- $\alpha$ ) in exhaled air [73, 74].

\section{Future directions}

Chemiluminescence analysers are currently expensive (US\$18,000-96,000) and this limits the applicability of the measurement in clinical practice. It is likely that costs will come down with increased release of analysers and that their size and portability can be improved.

Alternative techniques of detecting NO, such as electrochemical methods, may be developed with appropriate sensitivity and allow the development of smaller and cheaper detectors.

Nitrite and nitrate can be measured in expiratory condensate [75] and in induced sputum, and this would be a cheaper means of monitoring NO release in the lungs, although with the disadvantage of a delay in obtaining the results.

It is important that measurement of exhaled $\mathrm{NO}$ in inflammatory lung diseases is compared with other measurements of inflammation, including bronchial biopsies, bronchoalveolar lavage and inflammatory indices in induced sputum. The measurement is extremely sensitive in longitudinal studies, using pro- and anti-inflammatory interventions. Hence, this makes it very useful for individual monitoring. The clinical utility of exhaled NO also needs to be explored in longitudinal studies, with repeated measurements in the same patients and correlation with clinical parameters. Exhaled NO is promising as a means of following the clinical control of the disease, and in research for assessment of factors that increase and decrease inflammation. Exhaled NO may also be useful in epidemiological studies, although the specificity of the measurement may be a problem.

It is clear that exhaled NO is a potentially important measurement and the number of publications is rapidly increasing. It is of the utmost importance that these measurements are made under carefully standardized conditions if the information is to be of value and if comparisons of measurements between different laboratories are to be made. We hope that the proposed recommendations for measuring exhaled NO will, therefore, be of value and we intend to update them as more information becomes available.

\section{References}

1. Gustafsson LE, Leone AM, Persson MG, Wiklund NP, Moncada S. Endogenous nitric oxide is present in the exhaled air of rabbits, guinea-pigs and humans. Biochem Biophys Res Commun 1991; 181: 852-857.

2. Leone AM, Gustafsson LE, Francis PL, Persson MG, Wiklund NP, Moncada S. Nitric oxide is present in exhaled breath in humans: direct GC-MS confirmation. Biochem Biophys Res Commun 1994; 201: 883-887.

3. Barnes PJ, Belvisi MG. Nitric oxide and lung disease. Thorax 1993; 48: 1034-1043.

4. Barnes PJ, Liew FY. Nitric oxide and asthmatic inflammation. Immunol Today 1995; 16: 128-130.

5. Alving K, Weitzberg E, Lundberg JM. Increased amount of nitric oxide in exhaled air of asthmatics. Eur Respir $J$ 1993; 6: 1368-1370.

6. Kharitonov SA, Yates DH, Robbins RA, Logan-Sinclair $\mathrm{R}$, Shinebourne EA, Barnes PJ. Increased nitric oxide in exhaled air of asthmatic patients. Lancet 1994; 343 : $133-135$. 
7. Persson MG, Zetterstrom O, Agrenius V, Ihre E, Gustafsson LE. Single-breath nitric oxide measurements in asthmatic patients and smokers. Lancet 1994; 343: 146-147.

8. Kharitonov SA, Wells AU, O'Connor BJ, et al. Elevated levels of exhaled nitric oxide in bronchiectasis. Am J Respir Crit Care Med 1995; 151: 1889-1893.

9. Massaro AF, Mehta S, Lilly CM, Kobzik L, Reilly JJ, Drazen JM. Elevated nitric oxide concentrations in isolated lower airway gas of asthmatic subjects. Am J Respir Crit Care Med 1996; 153: 1510-1514.

10. Kharitonov SA, Chung KF, Evans DJ, O'Connor BJ, Barnes PJ. Increased exhaled nitric oxide in asthma is mainly derived from the lower respiratory tract. Am J Respir Crit Care Med 1996; 153: 1773-1780.

11. Barnes PJ, Kharitonov SA. Exhaled nitric oxide: a new lung function test. Thorax 1996; 51: 233-237.

12. Kharitonov SA, Barnes PJ. Exhaled nitric oxide: a marker of airway inflammation? Curr Opin Anaesthesiol 1996; 9: 542-548.

13. Lundberg JON, Weitzberg E, Lundberg JM, Alving K. Nitric oxide in exhaled air. Eur Respir J 1996; 9: 26712680.

14. Lundberg JON, Nordwall SL, Weitzberg E, Kollberg H, Alving K. Exhaled nitric paediatric asthma and cystic fibrosis. Arch Dis Child 1996; 75: 323-326.

15. Kharitonov SA, Yates DH, Barnes PJ. Inhaled glucocorticosteroids decrease nitric oxide in exhaled air of asthmatic patients. Am J Respir Crit Care Med 1996; 153: 454-457.

16. Balfour-Lynn IM, Laverty A, Dinwiddie R. Reduced upper airway nitric oxide in cystic fibrosis. Arch Dis Child 1996; 75: 319-322.

17. Massaro AF, Gaston B, Kita D, Fanta C, Stamler JS, Drazen JM. Expired nitric oxide levels during treatment of acute asthma. Am J Respir Crit Care Med 1995; 152: 800-803.

18. Robbins RA, Floreani AA, Von Essen SG, et al. Measurement of exhaled nitric oxide by three different techniques. Am J Respir Crit Care Med 1996; 153: 1631-1635.

19. Rutgers SR, Postma DS, van der Mark ThW, Koëter GH. Nitric oxide in exhaled air in COPD. Eur Respir $J$ 1996; 9 (Suppl. 23): 13s.

20. Dötsch J, Demirakça S, Terbrack HG, Hüls G, Rascher W, Kühl PG. Airway nitric oxide in asthmatic children and patients with cystic fibrosis. Eur Respir J 1996; 9: 2537-2540.

21. Cailes JB, Kharitonov SA, Yates D, Barnes PJ, Du Bois RM. Decreased endogenous nitric oxide in the exhaled air of systemic sclerosis patients. Thorax 1995; 50: 452P.

22. Lundberg JON, Rinder J, Weitzberg E, Lundberg JM, Alving K. Nasally exhaled nitric oxide in humans originates mainly in the paranasal sinuses. Acta Physiol Scand 1994; 152: 431-432.

23. Gerlach H, Rossaint R, Pappert D, Knorr M, Falke KJ. Autoinhalation of nitric oxide after endogenous synthesis in nasopharynx. Lancet 1994; 343: 518-519.

24. Dillon WC, Hampl V, Shultz PJ, Rubins JB, Archer SL. Origins of breath nitric oxide in humans. Chest 1996; 110: 930-938.

25. Lundberg JON, Farkas-Szallasi T, Weitzberg E, et al. High nitric oxide release in human paranasal sinuses. Nature Med 1995; 1: 370-373.

26. Lundberg JON, Weitzberg E, Rinder J, et al. Calciumdependent and steroid-resistant nitric oxide synthase activity in human paranasal sinus mucosa. Eur Respir J 1996; 9: 1344-1347.

27. Lundberg JON, Weitzberg E, Nordvall SL, Kuylenstierna R, Lundberg JM, Alving K. Primarily nasal origin of exhaled nitric oxide and absence in Kartagener's syndrome. Eur Respir J 1994; 7: 1501-1504.

28. Kharitonov SA, Rajakulasingam K, O'Connor BJ, Durham SR, Barnes PJ. Nasal nitric oxide is increased in patients with asthma and allergic rhinitis and may be modulated by nasal glucocorticosteroids. J Allergy Clin Immunol 1997; 99: 58-64.

29. Archer S. Measurement of nitric oxide in biological models. FASEB J 1993; 7: 349-360.

30. Fontijin A, Sabadell AJ, Ronco RJ. Homogenous chemiluminescent measurement of nitric oxide with ozone: implications for continuous selective monitoring of gaseous air pollutants. Anal Chem 1970; 42: 575-579.

31. Högman M, Strömberg S, Schedin U, Frostell C, Hedenstierna G, Gustafsson LE. Nitric oxide from the human respiratory tract effectively quantified by standardised single-breath measurements. Acta Physiol Scand 1997; 159: 345-346.

32. Persson MG, Lomngvist PA, Gustafsson LE. Positive end-expiratory pressure ventilation elicits increases in endogenously formed nitric oxide as detected in air exhaled by rabbits. Anesthesiology 1995; 82: 969-974.

33. American Thoracic Society. Standardization of Spirometry. 1994 Update. Medical Section of the American Lung Association. Am J Respir Crit Care Med 1995; 152: $1107-1136$.

34. Meijer RJ, Kerstjens HAM, Postma DS, Koëter GH, van der Mark ThW. Exhaled nitric oxide concentration is greatly augmented by alcohol containing disinfectant. Am J Respir Crit Care Med 1996; 153: A798.

35. Kimberly B, Nejadnik B, Giraud GD, Holden WE. Nasal contribution to exhaled nitric oxide at rest and during breathholding in humans. Am J Respir Crit Care Med 1996; 153: 829-836.

36. Borland C, Cox Y, Higenbottam TW. Measurement of exhaled nitric oxide in man. Thorax 1993; 48: 1160-1162.

37. Sharma VS, Taylor TG, Gardiner R. Reaction of nitric oxide with haem proteins and model compounds of haemoglobin. Biochem 1987; 26: 3837-3843.

38. Ogilvie CM, Forster RE, Blakemore WS, Morton JW. A standardised breathholding technique for the clinical measurement of the diffusing capacity of the lung for carbon monoxide. J Clin lnvest 1957; 36: 1-17.

39. Silkoff PE, McLean P, Slutsky AS, et al. Exhaled nitric oxide measured without a nasal component shows marked flow dependence. Am J Respir Crit Care Med 1997; 155: 260-267.

40. Imada M, Iwamoto J, Nonaka S, Kobayashi Y, Unno $\mathrm{T}$. Measurement of nitric oxide in human nasal airway. Eur Respir J 1996; 9: 556-559.

41. Trolin G, Anden T, Hedenstierna G. Nitric oxide in expired air at rest and during exercise. Acta Physiol Scand 1994; 151: 159-163.

42. Schedin U, Frostell C, Persson MG, Jakobsson J, Andersson G, Gustafsson LE. Contribution from upper and lower airways to exhaled endogenous nitric oxide in humans. Acta Anaesthesiol Scand 1995; 39: 327-332.

43. Lundberg JON. Airborne nitric oxide: inflammatory marker and aerocrine messenger in man. Acta Physiol Scand 1996; 157 (Suppl. 663): 1-47.

44. Cremona G, Higenbottam TW, Takao M, Hall L, Bower EA. Exhaled nitric oxide in isolated pig lungs. $J$ Appl Physiol 1995; 78: 59-63.

45. Schilling J, Holzer P, Guggenbach M, Gyurech D, Marathia K, Geroulans S. Reduced endogenous nitric oxide in the exhaled air of smokers and hypertensives. Eur Respir J 1994; 7: 467-471. 
46. Kharitonov SA, Barnes PJ. There is no nasal contribution to exhaled nitric oxide during exhalation against resistance or during breathholding. Thorax 1997; (in press).

47. European Respiratory Society. Standardisation of the measurement of transfer factor (diffusing capacity). Eur Respir J 1993; 6 (Suppl. 16): 41-52.

48. Schedin U, Norman M, Gustafsson LE, Herin P, Frostell C. Endogenous nitric oxide in the upper airways of healthy newborn infants. Ped Res 1996; 40: 148-151.

49. Rinder J, Lundberg JON, Änggård A, Alving K, Lundberg JM. Effects of topical nasal decongestants, L-arginine and nitric oxide synthase inhibition on nasal cavity nitric oxide levels and nasal cavity volume in man. Am $J$ Rhinol 1996; 157: 233-244.

50. Lewandowski K, Busch T, Lewandowski, M, Keske U, Gerlach H, Falke KJ. Evidence of nitric oxide in the exhaled gas of Asian elephants (Elephas maximus). Respir Physiol 1996; 106: 91-98.

51. Jilma B, Kastner J, Mensik C, et al. Sex differences in concentrations of exhaled nitric oxide and plasma nitrate. Life Sci 1996; 6: 469-476.

52. Phillips CR, Giraud GD, Holden W. Exhaled nitric oxide during exercise: site of release and modulation by ventilation and blood flow. J Appl Physiol 1996; 80: 18651871.

53. Campbell NT, Beres GA, Blasko TJ, Groth RH. Effect of water and carbon dioxide in chemiluminescent measurement of oxides of nitrogen. J Air Pollut Control Assoc 1982; 32: 533-535.

54. Zabielski MF, Seery DJ, Dodge LG. Influence of mass transport and quenching on nitric oxide chemiluminescent analysis. Environ Sci Technol 1984; 18: 88-92.

55. Bauer JA, Wald JA, Doran S, Soda D. Endogenous nitric oxide in expired air: effects of acute exercise in humans. Life Sci 1994; 55: 24, 1903-1909.

56. Persson MG, Wiklund NP, Gustafsson LE. Endogenous nitric oxide in single exhalations and the change during exercise. Am Rev Respir Dis 1993; 148: 1210-1214.

57. Lundberg JON, Rinder J, Weitzberg E, Alving K, Lundberg JM. Heavy physical exercise decreases nitric oxide levels in the nasal airways in man. Acta Physiol Scand 1997; 159: 51-57.

58. Tsujino I, Miyamoto K, Nishimura M, et al. Production of nitric oxide (NO) in intrathoracic airways of normal humans. Am J Respir Crit Care Med 1996; 154: 1370_ 1374.

59. Kharitonov SA, Robbins RA, Yates D, Keatings V, Barnes PJ. Acute and chronic effects of cigarette smoking on exhaled nitric oxide. Am J Respir Crit Care Med 1995; 152: 609-612.

60. Persson MG, Gustafsson LE. Ethanol can inhibit nitric oxide production. Eur J Pharmacol 1992; 224: 99100.
61. Yates DH, Kharitonov SA, Robbins RA, Thomas PS, Barnes PJ. The effect of alcohol ingestion on exhaled nitric oxide. Eur Respir J 1996; 9: 1130-1133.

62. Kharitonov SA, Logan-SinclairRB, BussetCM, Shinebourne EA. Peak expiratory nitric oxide differences in men and women: relation to the menstrual cycle. Br Heart J 1994; 72: 243-245.

63. Rosselli M, Imthurm B, Macas E, Keller PJ, Dubey RK. Circulating nitrite/nitrate levels increase with follicular development: indirect evidence for estradiol-mediated NO release. Biochem Biophys Res Commun 1994; 202 : $1643-1652$

64. Morris NH, Carroll S, Nicolaides KH, Steer PJ, Warren JB. Exhaled nitric oxide concentration and amniotic fluid nitrite concentration during pregnancy. Eur J Clin Invest 1995; 24: 138-141.

65. Morris NH, Sooranna SR, Steer PJ, Warren JB. The effect of the menstrual cycle on exhaled nitric oxide and urinary nitrate concentration. Eur J Clin Invest 1996; 26: 481-484.

66. Kharitonov SA, Yates DH, Barnes PJ. Increased nitric oxide in exhaled air of normal human subjects with upper respiratory infections. Eur Respir J 1995; 8: 295-297.

67. De Gouw HWFM, Grünberg K, Schot R, Dick EC, Sterk PJ. Exhaled nitric oxide (NO) increases following experimental rhinovirus 16 (RV16) infection in asthmatic subjects in vivo. Am J Respir Crit Care Med 1996; 153: A798.

68. Kharitonov SA, Lubec G, Lubec B, Hjelm M, Barnes PJ. L-arginine increases exhaled nitric oxide in normal human subjects. Clin Sci 1995; 88: 135-139.

69. Lundberg JON, Weitzberg E, Lundberg JM, Alving K. Intragastric nitric oxide production in humans: measurements in expelled air. Gut 1994; 35: 1543-1546.

70. Habib MP, Clements NC, Garewal HS. Cigarette smoking and ethane exhalation in humans. Am J Respir Crit Care Med 1994; 151: 1368-1372.

71. Dohlman AW, Black HR, Royall JA. Expired breath hydrogen peroxide is a marker of acute airway inflammation in pediatric patients with asthma. Am Rev Respir Dis 1993; 148: 955-960.

72. Dekhuijzen PRN, Aben KHH, Dekker I, et al. Increased concentrations of exhaled hydrogen peroxide in patients with stable and unstable COPD. Am J Respir Crit Care Med 1996; 153, A732.

73. Becher G, Winsel K, Beck E, Stresemann E. Leukotriene $\mathrm{B}_{4}$ in breathing condensate of patients with bronchopulmonary diseases and of normal patients. Appl Cardiopulm Pathophysiol 1995; 5: 215-219.

74. Winsel K, Becher G, Beck E. Inflammatory mediators in the breathing condensate of allergic asthmatics. Am J Respir Crit Care Med 1994; 149: A332.

75. Hunt J, Byrns RE, Ignarro LJ, Gaston B. Condensed expirate nitrite as a home marker for acute asthma. Lancet 1995; 4: 1235-1236. 